\title{
Leader-Based Workplace Health Interventions - A Before-After Study in Norwegian and Swedish Small-Scale Enterprises
}

\author{
Elisabeth Hansen, ${ }^{1}$ Bodil J. Landstad, ${ }^{1,2}$ Kjell Terje Gundersen, ${ }^{3}$ and Stig Vinberg ${ }^{1}$ \\ ${ }^{1}$ Department of Health Sciences, Mid Sweden University, Sweden, \\ ${ }^{2}$ Levanger Hospital, Nord-Trøndelag Hospital Trust, Norway \\ ${ }^{3}$ Faculty of Education, Nord University, Norway
}

\begin{abstract}
$\mathrm{T}$ he purpose of this study is to contribute to knowledge about leader-based workplace health interventions by investigating changes in psychosocial working conditions and health in Norwegian and Swedish small-scale enterprises (SSEs). The study also aims to investigate whether there are differences between position, and countries. In total, 30 leaders and 149 coworkers in 34 SSEs participated in two intervention and two reference groups. Leaders and coworkers completed the validated questionnaires (Nordic Questionnaire on Positive Organizational Psychology ([N-POP]), Work Experience Measurement Scale (WEMS), and Salutogenic Health Indicator Scale (SHIS), which cover different psychosocial working conditions and health outcomes. The interventions were carried out by advisors from occupational health services (OHSs) over a one-year period and consisted of analyses of health and psychosocial working conditions, company visits, education and networking meetings, including information and tools on issues such as leadership, work environment and health, and leadership support. The statistical methods used included principal component analyses, reliability tests, paired sample $t$ tests and three-way ANOVA. The results indicate a significant positive development concerning external job performance in the intervention groups. Regarding internal job performance, both the Norwegian intervention group and the reference group showed positive improvements. However, there were negative or nonsignificant developments for several of the psychosocial working conditions and health outcomes in the intervention groups. With regard to associations and interactions between the studied variables, there were significantly positive developments with regard to external job performance and sickness absences in the total intervention group. The study indicates that more thorough procedures and testing of leader-based interventions in SSES are required.
\end{abstract}

Keywords: psychosocial working conditions, health, leader-based interventions, small-scale enterprises

Small-scale enterprises (SSEs) are often considered to have limited economic and personal resources and a lack of knowledge about how to carry out workplace health interventions (Huuskonen, 2002; Vinberg, 2008; Wilson, DeJoy, Jorgensen, \& Crump, 1999). In addition, such enterprises have limited organisational mechanisms for communication and insufficient in-house resources for workplace health issues, and a perceived lack of evidence regarding the benefits of workplace interventions may discourage their efforts (Griffin, Hall, \& Watson, 2005). In view of these circumstances, it is likely that SSEs need outside support to implement workplace health interventions. Therefore, it is noteworthy that this enterprise group has a lower degree of access to resources such as occupational health services (OHS; Andersson \& Josephson, 2011).

However, researchers also note that SSEs have an advantageous context for promoting health due to their unique social, organisational and environmental attributes (Meggeneder, 2007). They have fewer people to accommodate, lower administrative costs and higher rates of coworker participation in change processes (Stokols, McMahan, \& Philips, 2001). Additionally, Jensen (2001) noted that the level of leader and coworker competence in SSEs is usually sufficient to effectively improve the work environment and cooperate with external resources. Researchers from the workplace health promotion area (Bjørnstad, 2013; Stokols

Address for correspondence: Elisabeth Hansen, Department of Health Sciences, Mid Sweden University, Kunskapens väg 8, Östersund, 83125, Sweden. 
et al., 2001) have made similar positive observations about change in such organisations by highlighting that small firms are employee-dependent and that employee participation is often better than in larger companies. The European Network for Workplace Health Promotion (ENWHP; [ENWHP, 2001]) has declared that small enterprises have a unique influence on coworkers' health because of the immediate control a small company owner can have over working conditions, the family atmosphere that is common to small and micro-enterprises, and the greater individual responsibility and simpler organisational structure in such organisations. The ENWHP proposed that any work concerning health in small companies should integrate the topic into daily managerial practices by involving all employees in decision-making processes, ensuring a good working atmosphere, recognising and rewarding good performance, and monitoring improvements - especially those related to the work organisation. These propositions are in line with approaches such as 'disability management' (Westmorland \& Buys, 2002) and 'workplace health management' (Shain \& Kramer, 2004), which note the importance of combining individual and organisational measures with a broader perspective for managing health.

In SSEs, the leaders have a primary role in how well occupational health issues are addressed by the organisation (Mattson, 2015). Additionally, research shows that leader behaviours and their own wellbeing is related to their coworkers' level of stress and wellbeing (Nyberg, Bernin, \& Theorell, 2005; Skakon, Nielsen, Borg, \& Guzman, 2010). Therefore, a focus in recent years has been on developing leader-based workplace health interventions, and there is support for the effectiveness of such interventions on coworkers' health (Kelloway \& Barling, 2010). One example is a Swedish study of an insurance company where the leaders held meetings that included education about workplace health issues during the second week of each month over one year (Theorell, Emdad, Arnetz, \& Weingarten, 2001). Compared to a control group of leaders in the same company, leaders and coworkers in the intervention group showed significantly improved biological stress measures and rated their opportunities to influence their work situation higher after the intervention period. According to the researchers, the important factors that led to the successful results included that the meetings were obligatory, they took place at the workplace over a long time period, and the leaders were able to support each other because they came from the same organisation (Theorell et al, 2001). Another example is an art-based intervention where the leaders held 12 meetings over 10 months that consisted of lectures and discussions about leadership issues (Romanowska et al., 2010). Compared to leaders in the conventional group, leaders in the art-based group showed significant improvement in stress resilience, agreeableness and leader- ship behaviour as evaluated by their subordinates (Romanowska et al., 2010).

Although research on SSEs has been a rapidly growing specialty over the past decade in Scandinavia and many other countries (Curran \& Blackburn, 2001; Davidsson, 2016), there are still few studies of workplace health issues and leadership in SSEs, particularly with regard to workplace health interventions (Moser \& Karlqvist, 2004; Witt, Olsen, \& Ablah, 2013). Most of the studies have examined leaders in larger organisations, but the circumstances may be different in SSEs. For example, being a leader in an SSE often involves long and irregular working hours (Gunnarsson, Andersson, \& Josephson, 2011), high levels of pressure on the leaders' time and great work demands (Nordenmark, Vinberg, \& Strandh, 2012). It is also remarkable that few workplace health intervention studies have used a longitudinal approach on leaders' and coworkers working life in general (Källestål et al., 2004; Torp, Eklund, \& Thorpenberg, 2011) and with a specific focus on small enterprises (Griffin et al., 2005; Lindstrom, Schrey, Ahonen, \& Kaleva, 2000).

The perspectives described above constitute the basis for this study, which is to contribute to knowledge about leader-based workplace health interventions in SSEs by examining changes in leaders and coworkers' self-rated health and psychosocial working conditions. The following research questions are addressed:

1. What effects with regard to leaders and coworkers' psychosocial working conditions and health can be observed after two different workplace health interventions have been carried out?

2. To what extent do group (intervention-reference), position (leader-coworker), and country (NorwaySweden) interact with psychosocial working conditions and health?

\section{Materials and Methods}

\section{Participants and Procedure}

The longitudinal panel data presented here is part of a research and development project focusing on leaderbased workplace health interventions in Norwegian and Swedish SSEs. The enterprises were recruited by two occupational health services in Norway and Sweden. The enterprises agreed to participate in a workplace health intervention project in SSEs. One selection criterion was that they were enterprises with less than 20 employees representing different sectors. Further criteria were that the enterprises employed both genders and that they were located in rural areas (comparable geographic regions). In the study, 9 Norwegian $(n=64)$ and 10 Swedish $(n=39) 34$ SSEs participated in two intervention groups, and 6 Norwegian $(n=46)$ and 9 Swedish $(n=30) 34$ SSEs were recruited as reference groups. In total, 259 coworkers and leaders 
answered three questionnaires before the interventions (May, 2014). Due to sick leave, permission, parental leave and job changes, 179 individuals (149 coworkers, 30 leaders; response rate 69\%) answered the same questionnaires after the performed interventions (May, 2015). The sample consisted only of those individuals who had been working in the enterprises during the study period and who completed the questionnaires at both measuring points. This selection made it possible to compare the results for the same individuals before and after the interventions. Written informed consent was obtained from each of the study participants in accordance with the Helsinki Declaration. The study was approved by the Regional Committee for Ethics (dnr $2014-28-31 \mathrm{M})$.

\section{Workplace Health Interventions}

Two workplace health intervention models were carried out in the participating SSEs: a Norwegian model, and a Swedish model. Both models were led by advisory personnel from the occupational health services, which are private establishments that provide services regarding health, vocational rehabilitation, and leader development and working environment issues. One goal of the project was to develop and implement models and methods for improving health and psychosocial working conditions for this enterprise group. Both models mainly focused on leadership competence with regard to health and psychosocial working conditions, but they also included individual-based components related to rehabilitation, lifestyle and physical activity. Thus, the interventions can be described as multicomponent interventions in accordance with the ENWHP (2007). The models consisted of investigations, networking meetings and leadership support and were quite similar, although there were some differences (see Figure 1). Differences were that the Norwegian model consisted of investigations and education activities for both leaders and coworkers, while the Swedish model was more focused on the leaders' working conditions; the Swedish model included medical examinations of leaders and a dialogue with an OHS psychologist; and the Swedish model also consisted of a larger number of networking meetings.

\section{Norwegian Intervention Model}

The Norwegian intervention model was carried out by advisors from a private establishment offering occupational health services to coworkers and leaders in nine SSEs. The first phase of the model focused on investigations of working conditions, health and lifestyle through questionnaires, company visits and physical fitness measures of the leaders. Advisors from the OHS unit pre-investigated health and psychosocial working conditions using a questionnaire and by interviewing a leader in each company to define the existing health and working environment status at the workplace. This procedure was carried out to collect background information and knowledge in order to develop a separate plan for each enterprise targeting the more efficient use of tools to achieve an improved health and psychosocial working environment together with more efficient leadership. The leaders also completed physical fitness tests, including body composition, a cycle ergometer test and measures of strength. These tests were carried out by personnel from the Swedish Winter Sports Research Centre, Mid Sweden University, who also gave the leaders both group and individual test results. This first phase of the model can be viewed as a motivational component for improvement and a base for the next phase.

The second phase consisted of a program for the leaders that was called 'Leadership in Modern Working Life', which included three meetings over a period of one year that each lasted three hours. The meetings included education, and discussions on issues such as psychosocial working conditions, leadership, collaboration, handling conflicts and work pressure. In each enterprise, there were additional meetings led by a consultant from the OHS. These meetings included educational sessions and discussions among the coworkers and leaders on three occasions (2-3 hours/occasion) about lifestyle, team development, communication, and work engagement, with one follow up on sickness absences.

The third phase consisted of individual leadership support from OHS personnel through dialogues in physical meetings and/or by telephone concerning health issues, psychosocial working conditions and leadership behaviour. Over the same one-year period, at 2 to 3 month intervals, several newsletters that included brief information regarding the project purpose, time schedules and activities involved in the project were sent out to the participating leaders and coworkers.

The fourth phase consisted of follow-up measures by the OHS unit and the Swedish Winter Sports Research Centre using the same methods as in the first phase. These results were presented by the OHS personnel at visits to each enterprise together with proposals for further improvements in health and the psychosocial working environment.

In the six reference enterprises, the leaders also completed before and after physical fitness tests, including body composition, a cycle ergometer test and measures of strength. The coworkers in the reference enterprises did not participate in the project.

\section{Swedish Intervention Model}

The Swedish intervention model was also carried out by advisors from a private establishment offering OHS aimed at leaders of the 10 intervention enterprises, while the 9 reference enterprises did not receive any 


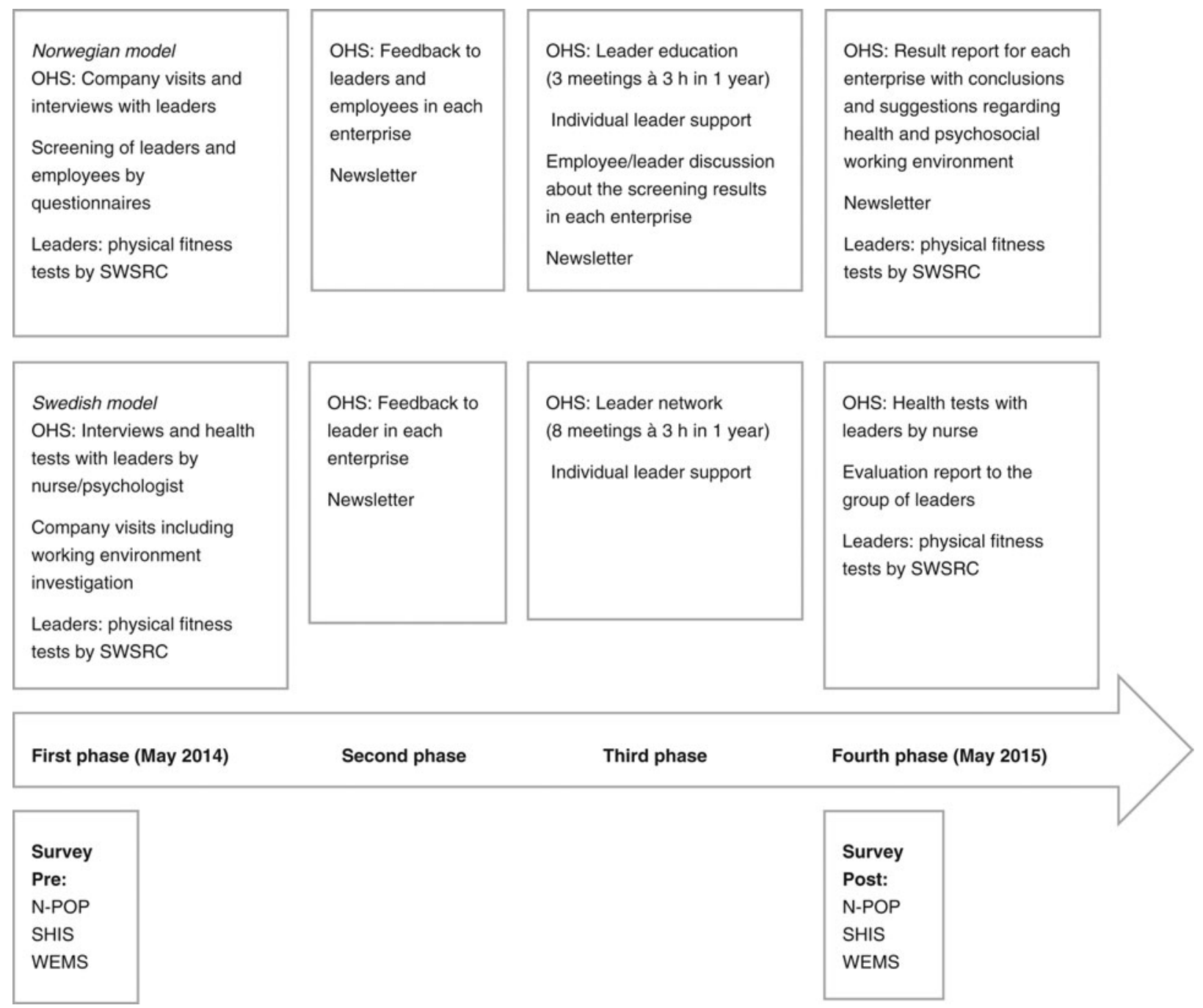

\section{FIGURE 1}

Flow-chart describing data collection and workplace health interventions in the study.

Note: SWSRC — Swedish Winter Sports Research Centre; OHS — occupational health services; N-POP — Nordic Questionnaire on Positive Organizational Psychology; WEMS - Work Experience Measurement Scale; SHIS — Salutogenic Health Indicator Scale.

intervention at this point. As in the Norwegian model, leaders in both the intervention and reference groups completed fitness tests, including body composition, a cycle ergometer test and measures of strength. These tests were also repeated at the end of the intervention period for both leader groups. These tests were carried out by personnel from the Swedish Winter Sports Research Centre, Mid Sweden University, which gave the leaders both group and individual test results. The Swedish intervention leaders also received basic medical examinations and a one-hour health talk with an occupational health nurse about how to improve their lifestyle and physical activity. In this first phase, consultants from the OHS also conducted investigations of occupational health and safety systems and working conditions through visits to each enterprise. These results were summarised and presented to each company. The leaders also had a meeting with an OHS psycholo- gist that included discussions about their leadership and their own working conditions.

In the second phase, all of the leaders from the intervention group were invited to networking meetings/educational sessions for a period of approximately one year. In total, eight meetings lasting 3 to 3.5 hours each were conducted, and they included issues related to the leaders' work-life balance, health-promoting leadership, and psychosocial working conditions with regard to how to solve conflicts and provide feedback to coworkers. The meetings also focused on techniques to help improve leadership, working conditions and the promotion of health at the workplaces. The presence of the leaders at these meetings varied: some leaders participated in all 8 meetings and some in only 3 meetings.

In the third phase, individual support from OHS personnel was provided through dialogues in physical meetings and/or by telephone concerning health is- 
sues, psychosocial working conditions and leadership behaviour. As in the Norwegian model, a newsletter about the activities involved in the project was provided to the participating enterprises.

The fourth phase consisted of follow-up measures by the OHS unit and the Swedish Winter Sports Research Centre using the same methods as in the first phase. At the end of the intervention period, the intervention leaders received a follow-up examination and a discussion with an occupational health nurse. The intervention ended with a report where the involved leaders provided an evaluation of the program conducted by the OHS advisors.

\section{Questionnaire Content and Indices}

In this study, we used three validated questionnaires for measuring psychosocial working conditions and health outcomes: Nordic Questionnaire on Positive Organizational Psychology (N-POP), the Work Experience Measurement Scale (WEMS) and the Salutogenic Health Indicator Scale (SHIS). Below, each questionnaire is described together with the constructed factors/indices.

N-POP was developed to measure positive factors at work, individual wellbeing and positive organisational wellbeing (Christensen, 2012). The dimensions of NPOP are based on 18 items and six factors in the beginning. After executing a principal component analysis (PCA) on the data, five factors were extracted covering 15 items. 'Innovative climate' included 3 items about making improvements at work, joint discussions about tasks and goals and feedback from customers (Cronbach's $\alpha=.76$ ) and ranged from 3 to 15 . There were five response alternatives, ranging from 1 (almost never) to 5 (very often). 'Work-life balance' included 2 items covering whether work demands interfered with family life and whether family demands interfered with work demands $(\alpha=.69)$ and ranged from 2 to10. There were 5 response alternatives, ranging from 1 (never) to 5 (very often). 'Internal job performance' included 3 items about expertise in job-related tasks, competence in different areas of the job and the ability to handle tasks with proficiency and perform well in the overall job $(\alpha=.78)$ and ranged from 3 to 15 . 'External job performance' included 4 items about volunteering to do things that were not formally required, making innovative suggestions to improve quality, helping others when their work load increases and helping other employees when they have been absent from work $(\alpha=.71)$ and ranged from 4 to 20 . These two factors had 5 response alternatives, ranging from 1 (never) to 5 (almost always). 'Sleep' included 3 items covering whether one fell asleep easily, slept soundly through the night and slept without waking up early in the morning $(\alpha=.51)$ and ranged from 3 to 15. There were 5 response alternatives, ranging from 1 (every night or almost every night) to 5 (never). The orig- inal sixth factor was 'Work engagement' and included 3 items, but it was removed after conducting the PCA. Additionally, one question covering 'Sickness absences', which ranged from 4 (never missed work) to 1 (missed 5 days or more because of illness), and one question covering 'Sickness presence', which ranged from 4 (never sick) to 1 (often present while sick), were included as dependent variables in the analyses. For all of the factors, low values indicate negative results and high values positive results.

The WEMS was developed to measure the multifaceted work experience from a Salutogenic health resource perspective (Nilsson, Bringsen, Andersson, \& Ejlertsson, 2010). The instrument originally consisted of 32 items, and there were 6-point Likert-type alternative responses ranging from 1 (disagree) to 6 (agree completely), with six factors extracted by PCA:

1. Management (MT): The manager creates interest in and commitment to work tasks; the manager consults the work team prior to making important decisions; the manager presents information about the department's vision with regard to team goals; the manager allocates work tasks fairly among the work team; the manager has the ability to make decisions when required; and my immediate manager is available when needed.

2. Reorganisation (RO): The reorganisation felt meaningful; the reorganisation was characterised by participation and involvement; I felt confident at work during the reorganisation; the reorganisation was a result of the work team's needs or desires; I was well informed during the reorganisation; and the reorganisation was characterised by open dialogue.

3. Internal work experience (IW): My work is meaningful; how great a challenge does your work offer? I progress in my work; my work involves various tasks; I do the work I am trained for; and I am happy to go to work.

4. Pressure of time (PT): I rarely have enough time to finish my tasks; I have enough time to finish my tasks without feeling pressed for time; and I often feel pressured to work overtime.

5. Autonomy (AY): I decide when tasks should be carried out; I decide what to do in terms of work tasks; I decide how the tasks are to be carried out; and I set the pace when carrying out my work tasks.

6. Supportive working conditions $(\mathrm{SW})$ : We encourage and support one another at work; we have a good work atmosphere; work routines are appropriate and well run; I receive feedback on my work; my employer invests in my wellbeing; I enjoy working here, and I receive advice and assistance from others when necessary.

In the present study, six factors were also extracted after conducting the PCA. Four of the original factors, Factor $1 \mathrm{MT}(\alpha$ pre $=.93)$, ranging from 6 to 36; Factor 
$2 \mathrm{RO}(\alpha$ pre $=.96)$, ranging from 6 to 36 ; Factor $4 \mathrm{PT}$ $(\alpha$ pre $=.84)$, ranging from 3 to 18 ; and Factor $5 \mathrm{AY}$ $(\alpha=.90)$, ranging from 4 to 24 , remained unchanged; while Factor 3 IW, ranging from 4 to 24, and Factor 6 SW, ranging from 5 to 30 , were reduced.

Factor 3 IW ( $\alpha$ pre $=.758)$ included: My work is meaningful; I progress in my work; my work involves various tasks; and I do the work I am trained for, whereas the items How great a challenge does your work offer? and I am happy to go to work were excluded. Factor $6 \mathrm{SW}(\alpha$ pre $=.88)$ included: We encourage and support one another at work; we have a good work atmosphere; work routines are appropriate and well run; I receive feedback on my work; and I enjoy working here, whereas the items My employer invests in my wellbeing and I receive advice and assistance from others were excluded.

Further, the WEMS questions, after extraction, were summed (ranging from 28-168) into a Total WEMS Scale Index $(\alpha$ pre $=.95)$, and category indices of 'Experience of work' (AY+SW+ IW), 'Organisational changes' $(\mathrm{PT}+\mathrm{SW}+\mathrm{MT}+\mathrm{RO})$, and 'Work progress' $(\mathrm{SW}+\mathrm{RO})$ were included in the further analysis.

SHIS was developed to measure health from a Salutogenic and holistic perspective (Bringsen, Andersson, \& Ejlertsson, 2009). This scale consists of nine (originally ten) items: (1) Perceived stress (felt calm, relaxed — felt uneasy/tense); (2) Illness (felt well — felt ill); (3) Energy, which measures energy experience (felt brisk - felt tired/exhausted) and energy level (had a lot of energy - had little energy); (4) Physical function (felt that my body has been functioning well in relation to my way of living - felt that my body has been functioning poorly in relation to my way of living); (5) State of happiness (felt merry - felt low-spirited/gloomy); (6) Psychosomatic function (slept well - had problems sleeping); (7) Expressions of feelings (found it easy to show feelings - had difficulties showing feelings); (8) Cognitive ability (found it easy to concentrate - had concentration difficulties); and (9) Social capacity (have been functioning well when in contact with other people - have been functioning poorly when in contact with other people).

A general question was used to introduce the items: 'How have you been feeling during the past four weeks?'. The response alternatives ranged from 1 (negatively) to 6 (positively) for each item, and the summed totals ranged from 9 to 54 .

A PCA was then performed. The varimax solution, rotated, was used for factor extraction, and the eigenvalue was set to $>1$ as a criterion. Internal consistency was explored using Cronbach's alpha. In the present study, from the SHIS data, two factors were extracted: Interactive function (Cronbach's $\alpha$ pre $=.87$ ) included Resolution, Expressions of feelings, Concentration, and Creativity, with a scale ranging from 4 to 24 , whereas the items State of happiness and Perceived stress were excluded. Second, Intrapersonal characteristics $(\alpha$ pre $=$ .88 included Illness and Physical function, with a scale ranging from 2 to 12, whereas the items for Social capacity, Energy level, Energy experience and Sleep were excluded. Further, the SHIS questions, after extraction, were summed (a total of 6 ) into a total SHIS Index $(\alpha$ pre $=.95)$, which ranged from 6 to 36 and was included in the further analysis.

For all WEMS and SHIS indices/factors, low values indicate negative results and high values positive results.

\section{Statistical Analyses}

IBM SPSS Statistics 23 was used to conduct the descriptive background analyses, including means, standard deviations, and number of subjects. Empirical validation (PCA) and reliability tests of Cronbach alpha were conducted to explore potentially similar high test scores when compared to the equivalent original tests supporting the scales. The dependent variables were examined for comparison between the groups using a paired sample $t$ test allocated between Norway and Sweden (leaders + coworkers) separately by assessing mean pre and post values, standard deviations, $t$ scores and $p$ values. Second, delta/diff mean values (post-pre), standard deviations, $t$ scores (equal variances not assumed) and $p$ values were used to compare the groups (intervention versus reference) after the interventions. For a more thorough investigation, a three-way ANOVA was conducted on the basis of the delta/diff mean values (post-pre) to identify associations, interactions and possible effects between the independent variables (group: intervention versus reference; country: Norway versus Sweden; position: leader versus coworker) and each of the dependent variables.

\section{Results}

Comparisons Between, and Separately, Pre-Post, Intervention and Reference Groups

In Table 1 descriptive background statistics are presented covering pre and post mean values and standard deviations for the Norwegian intervention group, the Swedish intervention group, the Norwegian reference group, and the Swedish reference group for the indices for Psychosocial working conditions and Health outcomes. The pre mean values for the studied dependent variable indices were fairly comparable for both groups.

By investigating the groups separately (Norwegian intervention leaders + coworkers, Swedish intervention leaders + coworkers, Norwegian reference group leaders + coworkers, Swedish reference group leaders + coworkers), the pre and post mean values could be compared using a paired sample $t$ test. The results indicated a negative development regarding Innovative climate for the Norwegian intervention group. Regarding Internal job performance, both the Norwe- 
TABLE 1

Descriptive Statistics for Intervention and Reference Groups, Pre and Post Mean Values, Standard Deviations ( $t$ scores and $p$ values for Each Variable Included in the Study)

\begin{tabular}{|c|c|c|c|c|c|c|c|c|c|c|c|c|c|}
\hline & & \multicolumn{4}{|c|}{ Intervention Group } & \multirow[b]{3}{*}{$t$} & \multirow[b]{3}{*}{$p$} & \multicolumn{4}{|c|}{ Reference Group } & \multirow[b]{3}{*}{$t$} & \multirow[b]{3}{*}{$p$} \\
\hline & & \multicolumn{2}{|c|}{ Pre } & \multicolumn{2}{|c|}{ Post } & & & \multicolumn{2}{|c|}{ Pre } & \multicolumn{2}{|c|}{ Post } & & \\
\hline & & M & $S D$ & M & $S D$ & & & M & $S D$ & M & $S D$ & & \\
\hline \multicolumn{14}{|l|}{ Pyschological working conditions } \\
\hline \multirow[t]{2}{*}{ Innovative climate } & NO & 10.30 & 2.29 & 9.39 & 2.49 & 3.42 & .001 & 10.27 & 1.99 & 10.18 & 2.19 & 0.37 & ns \\
\hline & SE & 10.74 & 3.03 & 10.66 & 2.85 & 0.244 & ns & 10.46 & 1.65 & 10.16 & 2.15 & 0.78 & ns \\
\hline \multirow[t]{2}{*}{ Work-life balance } & NO & 4.34 & 1.55 & 4.39 & 1.21 & -0.26 & ns & 3.84 & 1.33 & 3.91 & 1.11 & -0.45 & ns \\
\hline & SE & 4.28 & 1.35 & 4.07 & 1.36 & 1.07 & ns & 4.26 & 1.38 & 4.13 & 1.25 & 0.50 & ns \\
\hline \multirow[t]{2}{*}{ Internal job performance } & NO & 11.96 & 1.97 & 12.46 & 2.01 & -2.03 & .046 & 10.89 & 1.64 & 11.63 & 1.75 & -3.52 & .001 \\
\hline & SE & 13.00 & 1.45 & 13.15 & 1.94 & -0.64 & ns & 11.33 & 1.34 & 11.76 & 1.65 & -1.41 & ns \\
\hline \multirow[t]{2}{*}{ External job performance } & NO & 15.09 & 2.18 & 16.01 & 2.50 & -3.66 & .001 & 15.02 & 2.02 & 15.10 & 1.86 & -0.29 & ns \\
\hline & SE & 15.02 & 2.77 & 17.23 & 2.63 & -5.88 & .000 & 14.96 & 1.69 & 15.23 & 2.12 & -0.78 & ns \\
\hline \multirow[t]{2}{*}{ Management } & NO & 29.51 & 5.68 & 27.56 & 6.45 & 2.51 & .015 & 28.61 & 4.83 & 27.11 & 5.49 & 2.15 & .037 \\
\hline & SE & 27.60 & 7.53 & 25.73 & 8.13 & 1.72 & ns & 29.62 & 5.19 & 29.45 & 5.98 & 0.187 & ns \\
\hline \multirow[t]{2}{*}{ Reorganisation } & NO & 26.07 & 7.06 & 24.95 & 7.35 & 1.22 & ns & 25.52 & 6.41 & 24.93 & 6.04 & 0.922 & ns \\
\hline & SE & 23.51 & 9.13 & 23.48 & 9.54 & 0.24 & ns & 28.83 & 6.36 & 29.53 & 4.69 & -0.92 & ns \\
\hline \multirow[t]{2}{*}{ Internal work experience } & NO & 19.81 & 3.44 & 20.18 & 3.64 & -0.97 & ns & 20.17 & 2.33 & 19.76 & 2.86 & 1.30 & ns \\
\hline & SE & 18.84 & 3.65 & 18.69 & 3.58 & 0.36 & ns & 20.1 & 3.67 & 20.26 & 3.59 & -0.37 & ns \\
\hline \multirow[t]{2}{*}{ Pressure of time } & NO & 12.51 & 3.41 & 11.81 & 3.48 & 1.84 & ns & 11.63 & 3.68 & 11.56 & 3.22 & 0.14 & ns \\
\hline & SE & 12.02 & 4.25 & 12.15 & 3.71 & -0.21 & ns & 11.23 & 3.32 & 11.93 & 3.34 & -1.29 & ns \\
\hline \multirow[t]{2}{*}{ Autonomy } & NO & 17.21 & 4.12 & 15.76 & 4.54 & 2.65 & .010 & 15.3 & 4.05 & 14.17 & 4.53 & 1.80 & ns \\
\hline & SE & 17.97 & 4.62 & 17.74 & 4.49 & 0.47 & ns & 19.56 & 4.19 & 19.13 & 4.16 & 0.99 & ns \\
\hline Supportive working conditions & NO & 24.21 & 4.28 & 23.23 & 4.43 & 1.73 & ns & 22.41 & 4.00 & 21.71 & 4.32 & -0.45 & ns \\
\hline & SE & 23.58 & 4.58 & 22.41 & 5.04 & 2.22 & .032 & 24.86 & 3.89 & 25.06 & 4.44 & -0.37 & ns \\
\hline WEMS Total & NO & 128.91 & 20.21 & 124.30 & 19.70 & 1.89 & ns & 123.36 & 17.82 & 119.00 & 18.29 & 2.49 & .016 \\
\hline & SE & 125.20 & 23.29 & 121.50 & 24.80 & 1.22 & ns & 135.41 & 19.67 & 136.40 & 20.6 & -0.433 & ns \\
\hline WEMS Experience of work & NO & 61.25 & 8.96 & 59.18 & 8.63 & 1.79 & ns & 57.89 & 8.00 & 55.65 & 8.42 & 2.28 & .027 \\
\hline & SE & 60.41 & 10.19 & 58.84 & 10.80 & 1.61 & ns & 64.53 & 10.08 & 64.46 & 9.95 & 0.06 & ns \\
\hline WEMS Work progress & NO & 50.29 & 10.02 & 48.18 & 10.90 & 1.62 & ns & 47.93 & 9.09 & 46.65 & 9.39 & 1.59 & ns \\
\hline & SE & 47.10 & 12.67 & 45.89 & 14.20 & 0.99 & ns & 53.7 & 9.27 & 54.60 & 7.96 & -0.82 & ns \\
\hline WEMS Organisational change & NO & 92.36 & 16.47 & 88.44 & 16.60 & 1.97 & ns & 88.04 & 14.75 & 85.25 & 15.03 & 1.95 & ns \\
\hline & SE & 88.16 & 19.53 & 84.90 & 20.40 & 1.30 & ns & 96.37 & 12.76 & 97.33 & 14.64 & -0.52 & ns \\
\hline Health & & & & & & & & & & & & & \\
\hline SHIS Interactive function & NO & 17.06 & 3.93 & 17.12 & 4.35 & -0.10 & ns & 18.02 & 3.15 & 17.69 & 2.98 & 0.72 & ns \\
\hline & SE & 18.17 & 4.40 & 17.82 & 4.00 & 0.52 & ns & 18.03 & 2.83 & 18.30 & 3.53 & -0.48 & ns \\
\hline SHIS Intrapersonal characteristics & NO & 8.98 & 2.49 & 8.57 & 2.64 & 1.13 & ns & 9.63 & 2.16 & 8.97 & 2.58 & 1.83 & ns \\
\hline & SE & 9.92 & 2.01 & 9.12 & 2.51 & 2.40 & .021 & 9.43 & 1.77 & 9.53 & 2.38 & -0.31 & ns \\
\hline SHIS Total & NO & 34.95 & 7.88 & 34.45 & 8.54 & 0.43 & ns & 36.89 & 6.42 & 35.32 & 6.81 & 1.71 & ns \\
\hline & SE & 36.58 & 7.78 & 35.25 & 7.70 & 1.14 & ns & 36.36 & 5.53 & 36.76 & 7.11 & -0.37 & ns \\
\hline Sickness absence & NO & 2.89 & 0.96 & 2.83 & 0.82 & 0.46 & ns & 2.93 & 1.02 & 2.70 & 1.17 & 1.5 & ns \\
\hline & SE & 3.44 & 0.71 & 3.33 & 0.86 & 0.78 & ns & 2.83 & 1.08 & 2.27 & 1.2 & 2.28 & .030 \\
\hline Sickness presence & NO & 3.03 & 0.97 & 2.95 & 0.99 & 0.59 & ns & 3.13 & 0.93 & 2.93 & 1.12 & 1.1 & ns \\
\hline & SE & 3.18 & 0.90 & 2.95 & 1.05 & 2.04 & .048 & 2.73 & 1.08 & 2.77 & 1.13 & -0.13 & ns \\
\hline Sleep & NO & 11.03 & 2.49 & 10.85 & 2.66 & 0.48 & ns & 10.86 & 2.85 & 10.78 & 2.81 & 0.23 & ns \\
\hline & SE & 11.48 & 2.29 & 10.53 & 2.69 & 2.19 & .034 & 11.53 & 2.92 & 10.4 & 2.62 & 1.68 & ns \\
\hline
\end{tabular}

Note: $N=179$. NO = Norway; SE = Sweden; Leaders and coworkers' pre and post mean and standard deviation for the dependent variables of Psychosocial working conditions (N-POP, WEMS) and Health (SHIS). 
gian intervention group and the Norwegian reference group showed positive improvements. Regarding External job performance for both intervention groups, a positive development was observed. The results indicated a negative development regarding Management for both the Norwegian intervention group and the Norwegian reference group. Regarding WEMS total, a positive development was found for the Norwegian reference group. For Autonomy, a negative development was observed for the Norwegian intervention group. Regarding Supportive working conditions, a negative development was also observed for the Swedish intervention group. Regarding WEMS Experience of work, a negative development was found for the Norwegian reference group.

Health outcomes in the Swedish intervention group seemed to develop in a negative direction concerning the SHIS: Intrapersonal characteristics, Sickness presence and Sleep.

\section{Effects of Interventions (Comparing Diff Mean Values [Post-Pre] for Intervention Group and Reference Group)}

To examine the effects of the interventions between the intervention groups and the reference groups, a simple comparison of the mean delta values (post-pre) was carried out using an independent sample $t$ test on the data (see Table 2). The results of the statistical analyses indicated a significant negative development regarding innovative climate in the Norwegian intervention group compared to the Norwegian reference group. Concerning External job performance, both the Norwegian intervention group, compared to the reference group, and the Swedish intervention group, compared to the reference group, showed positive development. No other significant results were found at this point for the other indices related to Psychosocial working conditions and Health outcomes.

\section{Associations and interactions between independent and dependent variables}

Further analyses were conducted on the Psychosocial working conditions and Health outcomes by investigating different independent variables (Group: intervention-reference, Position: leader-coworker, country: Norway-Sweden) adjusted/controlled for each other (e.g., size or other irregularities). Table 3 to Table 6 present the significant associations and interactions between the independent variables and the dependent variables Psychosocial working conditions and Health outcomes.

For Psychosocial working conditions, the Group independent variable (intervention vs reference) and the Position independent variable (leaders vs coworkers) were significantly associated significantly with External job performance $(F=5.969 ; p=.016$ and $F=6.531$, $p=.011$, respectively; see Table 3 ). The intervention group scored more positive than the reference group (mean values: 1.070 vs 0.069) regarding External job performance, while the coworker group scored more positive than the leader group (mean values: 1.093 vs 0.046).

Country was associated significantly with time $(F=6.335, p=.013$; see Table 4). Sweden's scores were higher than Norway's scores (mean values: 1.089 vs -0.540$)$. The interaction between position and country with pressure of time was significant $(F=5.161$, $p=.024)$. Swedish leaders had the highest scores (mean value $=2.349)$, and Norwegian leaders had the lowest scores (mean values $=-0.750$ ).

Concerning health outcomes, country was significantly associated with Sleep $(F=8.771, p=.003)$. The Norwegian participants slept better than those from Sweden (mean values: 0.486 vs -1.256 ; see Table 5). The two-way interactions between position and country had a significantly effect on the dependent variable of Sleep $(F=4.373, p=.038)$. Norwegian leaders had the highest scores (mean value $=1.312$ ), and Swedish leaders had the lowest scores (mean value $=-1.659$ ).

Group was significantly associated with Sickness absences $(F=5.005, p=.027$; see Table 6$)$. The intervention group scores indicate fewer days away from work compared to the reference group scores, which indicate more absences (mean values: -0.124 vs -0.615 ).

\section{Discussion}

The purpose of this study was to contribute to knowledge about how leader-based workplace health interventions affect coworkers and leaders' psychosocial working conditions and health in SSEs. This topic is of particular importance due to the limited workplace health research on SSEs (Breuker, 2001) and because it is often stated that SSEs have insufficient competence and resources to engage in health improvement processes (Eakin, Lamm, \& Limborg, 2000; Walters, 2001; Vinberg, 2008).

The finding that there was no clear trend in the data and only limited differences between the intervention and reference groups with regard to the constructed indices for psychosocial working conditions and health outcomes has several possible explanations. The descriptive data show relatively high pre mean levels for both groups in comparison to other studies (Bringsen et al., 2009; Nilsson et al., 2010), which makes it more difficult to further improve psychosocial working conditions and health among coworkers and leaders. The general trends in Norwegian and Swedish working life during the follow-up period were also partly characterised by, e.g., increasing work demands and sickness absences (Aronsson, Johansen, Marklund, Rønning, \& Solheim, 2015). Another explanation could be the relatively short time period for the pre-post tests; some 
TABLE 2

Independent $t$ test for Comparison of the Intervention Group (Leaders and Coworkers [NO and SE]) and Reference Group (Leaders and Coworkers [NO and SE]), Diff Mean (Post-Pre) Values, Standard Deviation, $t$ scores and $p$ values

\begin{tabular}{|c|c|c|c|c|c|c|c|c|c|}
\hline & \multirow[b]{2}{*}{$C L+C W$} & \multicolumn{3}{|c|}{$\begin{array}{l}\text { Intervention Group } \\
\text { Diff (Post-Pre) }\end{array}$} & \multicolumn{3}{|c|}{$\begin{array}{c}\text { Reference Group } \\
\text { Diff (Post-Pre) }\end{array}$} & \multirow[b]{2}{*}{$t$} & \multirow[b]{2}{*}{$p$} \\
\hline & & $n$ & M & $S D$ & $n$ & M & $S D$ & & \\
\hline \multicolumn{10}{|l|}{ Pyschological working conditions } \\
\hline \multirow{2}{*}{ Innovative climate } & NO & 63 & -0.904 & 2.1 & 44 & -0.090 & 1.59 & -2.27 & .025 \\
\hline & SE & 39 & -0.076 & 1.96 & 30 & -0.300 & 2.10 & 0.044 & ns \\
\hline \multirow[t]{2}{*}{ Work-life balance } & NO & 64 & 0.046 & 1.44 & 46 & 0.065 & 0.97 & -0.08 & ns \\
\hline & SE & 39 & -0.205 & 1.19 & 30 & -0.133 & 1.45 & -0.21 & ns \\
\hline \multirow[t]{2}{*}{ Internal job performance } & NO & 64 & 0.500 & 1.96 & 46 & 0.739 & 1.42 & -0.74 & ns \\
\hline & SE & 39 & 0.153 & 1.49 & 30 & 0.433 & 1.67 & -0.71 & ns \\
\hline \multirow[t]{2}{*}{ External job performance } & NO & 64 & 0.921 & 2.01 & 46 & 0.087 & 1.98 & 2.16 & .033 \\
\hline & SE & 39 & 2.205 & 2.34 & 30 & 0.266 & 1.85 & 3.83 & .000 \\
\hline \multirow[t]{2}{*}{ Management } & NO & 58 & -1.948 & 5.89 & 44 & -1.500 & 4.62 & -0.43 & ns \\
\hline & SE & 30 & -1.866 & 5.92 & 24 & -0.166 & 4.36 & -1.21 & ns \\
\hline \multirow[t]{2}{*}{ Reorganisation } & NO & 64 & -1.125 & 7.33 & 46 & -0.587 & 4.31 & -0.48 & ns \\
\hline & SE & 39 & -0.025 & 6.53 & 30 & 0.700 & 4.12 & -0.56 & ns \\
\hline \multirow[t]{2}{*}{ Internal work experience } & NO & 64 & 0.375 & 3.06 & 46 & -0.413 & 2.14 & 1.58 & ns \\
\hline & SE & 39 & -0.153 & 2.6 & 30 & 0.166 & 2.40 & -0.52 & ns \\
\hline \multirow[t]{2}{*}{ Pressure of time } & NO & 64 & -0.703 & 3.05 & 46 & -0.065 & 3.09 & -1.07 & ns \\
\hline & SE & 39 & 0.128 & 3.72 & 30 & 0.700 & 2.97 & -0.70 & ns \\
\hline \multirow[t]{2}{*}{ Autonomy } & NO & 64 & -1.453 & 4.38 & 46 & -1.130 & 4.24 & -0.38 & ns \\
\hline & SE & 39 & -0.230 & 3.01 & 30 & -0.433 & 2.38 & 0.31 & ns \\
\hline \multirow[t]{2}{*}{ Supportive working conditions } & NO & 64 & -0.984 & 4.54 & 46 & -0.695 & 2.68 & -0.41 & ns \\
\hline & SE & 39 & -1.179 & 3.31 & 30 & 0.200 & 2.96 & -1.82 & ns \\
\hline \multirow[t]{2}{*}{ WEMS Total } & NO & 58 & -4.586 & 18.48 & 44 & -4.318 & 11.46 & -0.90 & ns \\
\hline & SE & 30 & -3.666 & 16.45 & 24 & 1.041 & 11.78 & -1.22 & ns \\
\hline \multirow[t]{2}{*}{ WEMS Experience of work } & NO & 64 & -2.062 & 9.19 & 46 & -2.239 & 6.64 & 0.11 & ns \\
\hline & SE & 39 & -1.564 & 6.04 & 30 & -0.066 & 5.38 & -1.08 & ns \\
\hline \multirow[t]{2}{*}{ WEMS Work progress } & NO & 64 & -2.109 & 10.38 & 46 & -1.282 & 5.46 & -0.54 & ns \\
\hline & SE & 39 & -1.205 & 7.57 & 30 & 0.900 & 5.96 & -1.29 & ns \\
\hline \multirow[t]{2}{*}{ WEMS Organisational change } & NO & 58 & -3.913 & 15.09 & 44 & -2.795 & 9.50 & -0.45 & ns \\
\hline & SE & 30 & -3.266 & 13.66 & 24 & 0.958 & 8.99 & -1.36 & ns \\
\hline \multicolumn{10}{|l|}{ Health } \\
\hline \multirow[t]{2}{*}{ SHIS Interactive function } & NO & 64 & 0.062 & 4.56 & 46 & -0.326 & 3.04 & 0.53 & ns \\
\hline & SE & 39 & -0.359 & 3.92 & 30 & 0.266 & 3.03 & -0.74 & ns \\
\hline SHIS Intrapersonal characteristics & NO & 64 & -0.406 & 2.86 & 46 & -0.652 & 2.4 & 0.48 & ns \\
\hline & SE & 39 & -0.794 & 2.06 & 30 & 0.100 & 1.76 & -1.93 & ns \\
\hline SHIS Total & NO & 64 & -0.500 & 9.29 & 46 & -1.565 & 6.19 & 0.72 & ns \\
\hline & SE & 39 & -1.333 & 7.28 & 30 & 0.400 & 5.79 & -1.10 & ns \\
\hline Sickness absence & NO & 64 & -0.078 & 1.04 & 46 & -0.195 & 1.20 & 0.53 & ns \\
\hline & SE & 39 & -0.230 & 0.70 & 30 & 0.033 & 1.37 & -0.95 & ns \\
\hline Sickness presence & NO & 64 & -0.062 & 1.06 & 46 & -0.239 & 1.07 & 0.85 & ns \\
\hline & SE & 39 & -0.230 & 0.70 & 30 & 0.033 & 1.37 & 1.65 & ns \\
\hline Sleep & NO & 64 & -0.171 & 2.83 & 46 & -0.087 & 2.55 & -0.16 & ns \\
\hline & SE & 39 & -0.948 & 2.69 & 30 & -1.133 & 3.69 & 0.23 & ns \\
\hline
\end{tabular}

Note: $N=179 . n=$ number of participants for the dependent variables. $\mathrm{C}=$ Country; $\mathrm{NO}=$ Norway, $\mathrm{SE}=$ Sweden. $\mathrm{L}=\mathrm{Leaders}, \mathrm{CW}=\mathrm{Cow}$ (17ker. Diff (post-pre) Mean, $S D, t$ score (equal variances not assumed) and $p \leq .05$ (2-tailed) for each dependent variable index of Psychosocial working conditions (N-POP, WEMS) and Health (SHIS). 
TABLE 3

Associations Between Group (Intervention/Reference), Position (Leader/Coworker) and Country (Norway/Sweden) and Effect on the Dependent Variable External Job Performance (Diff-Scores Between Post/Pre Tests, Three-Way ANOVA)

\begin{tabular}{|c|c|c|c|c|c|c|}
\hline \multirow{2}{*}{ Independent Variable } & & \multirow[b]{2}{*}{ Mean } & \multicolumn{2}{|c|}{$95 \% \mathrm{Cl}$} & \multirow[b]{2}{*}{$F$} & \multirow[b]{2}{*}{ Sig. } \\
\hline & & & $\mathrm{LL}$ & UL & & \\
\hline \multirow[t]{3}{*}{ Group } & & & & & 5.969 & .016 \\
\hline & Intervention & 1.070 & 0.539 & 1.601 & & \\
\hline & Reference & 0.069 & -0.540 & 0.679 & & \\
\hline \multirow[t]{3}{*}{ Position } & & & & & 6.531 & .011 \\
\hline & Leader & 0.046 & -0.686 & 0.778 & & \\
\hline & Coworker & 1.093 & 0.750 & 1.436 & & \\
\hline \multirow[t]{3}{*}{ Country } & & & & & 0.970 & ns \\
\hline & Norway & 0.368 & -0.206 & 0.941 & & \\
\hline & Sweden & 0.771 & 0.201 & 1.341 & & \\
\hline
\end{tabular}

Note: $N=177 . n s=$ not significant; bold values: significant $\leq .05$.

TABLE 4

Associations and Interactions Between Group (Intervention/Reference), Position (Leader/Coworker) and Country (Norway/Sweden) With Pressure of Time (Diff Scores Between Post/Pre Tests, Three-Way ANOVA)

\begin{tabular}{|c|c|c|c|c|c|c|}
\hline \multirow[b]{2}{*}{ Independent Variable } & & \multirow[b]{2}{*}{ Mean } & \multicolumn{2}{|c|}{$95 \% \mathrm{Cl}$} & \multirow[b]{2}{*}{$F$} & \multirow[b]{2}{*}{ Sig. } \\
\hline & & & $\mathrm{LL}$ & UL & & \\
\hline \multirow[t]{3}{*}{ Group } & & & & & 1.347 & ns \\
\hline & Intervention & -0.101 & -0.941 & 0.738 & & \\
\hline & Reference & 0.65 & -0.313 & 1.613 & & \\
\hline \multirow[t]{3}{*}{ Position } & & & & & 2.636 & ns \\
\hline & Leader & 0.8 & -0.357 & 1.956 & & \\
\hline & Coworker & -0.251 & -0.793 & 0.291 & & \\
\hline \multirow[t]{3}{*}{ Country } & & & & & 6.335 & .013 \\
\hline & Norway & -0.54 & -1.446 & 0.366 & & \\
\hline & Sweden & 1.089 & 0.188 & 1.989 & & \\
\hline \multirow[t]{5}{*}{ Position*Country } & & & & & 5.161 & .024 \\
\hline & Leader NO & -0.75 & -2.442 & 0.942 & & \\
\hline & Leader SE & 2.349 & 0.771 & 3.928 & & \\
\hline & Coworker NO & -0.33 & -0.979 & 0.318 & & \\
\hline & Coworker SE & -0.172 & -1.04 & 0.696 & & \\
\hline
\end{tabular}

Note: $N=179$. $N O=$ Norway; $S E=$ Sweden; $n s=$ not significant; bold values: significant $\leq .05$.

studies have noted a need to follow the effects of workplace interventions over longer time periods (Theorell et al., 2001; von Thiele Schwarz, Lindfors, \& Lundberg, 2008). An explanation could also be that although the networking and education meetings were valuable for the leaders, it is crucial that higher leader competence results in concrete actions in the enterprises with regard to improving their own and their coworkers' working conditions and health. This step can be particularly difficult in SSEs because they often lack resources to engage in workplace health change processes (Hasle \& Limborg, 2006; Wilson et al., 1999; Vinberg \& Gelin, 2005). Research also shows that the presence of leaders in the educational activities of the interventions is im- portant to obtaining good results (Theorell et al., 2001; von Thiele Schwarz et al., 2008). In the actual study, some of the leaders only participated in the networking meetings to a limited extent.

However, it is noteworthy that there were significant improvements in the intervention group in comparison to the reference group regarding external job performance and sickness absences. The fact that in comparison to the leaders, the coworkers rated their changes in job performance at a significantly higher level indicate intervention effects among the coworkers concerning (e.g., innovative suggestions and helping colleagues with work tasks). This result, together with the positive effects on sickness absences for the inter- 
TABLE 5

Associations and Interactions Between Group (Intervention/Reference), Position (Leader/Coworker) and Country (Norway/Sweden) With Dependent Variable Sleep (Diff Scores Between Post/Pre Tests, Three-Way ANOVA)

\begin{tabular}{|c|c|c|c|c|c|c|}
\hline \multirow{2}{*}{ Independent Variable } & & \multirow[b]{2}{*}{ Mean } & \multicolumn{2}{|c|}{$95 \% \mathrm{Cl}$} & \multirow[b]{2}{*}{$F$} & \multirow[b]{2}{*}{ Sig. } \\
\hline & & & $\mathrm{LL}$ & UL & & \\
\hline \multirow[t]{3}{*}{ Group } & & & & & .148 & ns \\
\hline & Intervention & -0.272 & -1.035 & 0.491 & & \\
\hline & Reference & -0.498 & -1.373 & 0.377 & & \\
\hline \multirow[t]{3}{*}{ Position } & & & & & .540 & ns \\
\hline & Leader & -0.173 & -1.224 & 0.878 & & \\
\hline & Coworker & -0.597 & -1.089 & -0.105 & & \\
\hline \multirow[t]{3}{*}{ Country } & & & & & 8.771 & .003 \\
\hline & Norway & 0.486 & -0.337 & 1.309 & & \\
\hline & Sweden & -1.256 & -2.074 & -0.437 & & \\
\hline \multirow[t]{5}{*}{ Position*Country } & & & & & 4.373 & .038 \\
\hline & Leader NO & 1.312 & -0.225 & 2.850 & & \\
\hline & Leader SE & -1.659 & -3.093 & -0.224 & & \\
\hline & Coworker NO & -0.341 & -0.930 & 0.248 & & \\
\hline & Coworker SE & -0.853 & -1.642 & -0.064 & & \\
\hline
\end{tabular}

Note: $N=177$. $N O=$ Norway; $S E=$ Sweden; $n s=$ not significant; bold values: significant $\leq .05$.

TABLE 6

Associations Between Group (Intervention/Reference), Position (Leader/Coworker) and Country (Norway/Sweden) With Sickness Absences (Diff Scores Between Post/Pre Tests, Three-Way ANOVA)

\begin{tabular}{|c|c|c|c|c|c|c|}
\hline \multirow[b]{2}{*}{ Independent Variable } & & \multirow[b]{2}{*}{ Mean } & \multicolumn{2}{|c|}{$95 \% \mathrm{Cl}$} & \multirow[b]{2}{*}{$F$} & \multirow[b]{2}{*}{ Sig. } \\
\hline & & & $\mathrm{LL}$ & UL & & \\
\hline \multirow[t]{3}{*}{ Group } & & & & & 5.005 & .027 \\
\hline & Intervention & -0.124 & -0.409 & 0.160 & & \\
\hline & Reference & -0.615 & -0.942 & -0.289 & & \\
\hline \multirow[t]{3}{*}{ Position } & & & & & 2.841 & ns \\
\hline & Leader & -0.555 & -0.947 & -0.162 & & \\
\hline & Coworker & -0.185 & -0.368 & -0.001 & & \\
\hline \multirow[t]{3}{*}{ Country } & & & & & 0.024 & ns \\
\hline & Norway & -0.353 & -0.660 & -0.046 & & \\
\hline & Sweden & -0.387 & -0.692 & -0.081 & & \\
\hline
\end{tabular}

Note: $N=179 . n s=$ not significant; bold values: significant $\leq .05$.

vention groups, is in line with other studies examining the effects of psychosocial working conditions on both wellbeing and organisational outcomes (Anderzén \& Arnetz, 2005; Schwartz et al., 2012).

The findings that one country (Norway) was significantly associated with better sleep outcomes, particularly among the leaders, and that pressure of time was significantly associated with better outcomes for Sweden and particularly their leaders are somewhat contradictory. Comprehensive research has shown relationships between pressure of time and negative health outcomes such as sleep problems (Åkerstedt et al., 2002). These results open up avenues for further research and indicate the importance of taking contextual country- related factors into account when studying the effects of interventions.

Although the research is limited with regard to workplace health interventions, several researchers have indicated a need for a holistic approach when individual- and organisational-based measures are combined (Dellve, Skagert, \& Vilhelmsson, 2007; ENWHP, 2007; Grawitch, Gottschalk, \& Munz, 2006). The importance of health-promoting leadership and participation from both leaders and coworkers has also been verified in earlier research (Shain \& Kramer, 2004). Research also shows that leader-based interventions through networking meetings and education can contribute to improvements for both leaders and 
coworkers (Romanowska et al., 2010; Theorell et al., 2001). However, our study results indicate a specific challenge in implementing these findings in SSEs. In another study, we interviewed the leaders, and the findings show that they are conscious of the importance of psychosocial working conditions and health issues, but that they lack the competence and resources to work on these issues (Landstad et al., in press). Therefore, it is important to obtain support from occupational health services and other health and rehabilitation consultants, particularly for SSEs. Research shows that a continuous dialogue between an enterprise and the OHS is important, and the OHS needs to be flexible to obtain good results (Schmidt, Sjöström, \& Antonson, 2011).

\section{Conclusion}

Leader-based workplace health interventions for leaders and coworkers regarding psychosocial working conditions and health in SSEs seem to be effective in this study to only a limited extent. The time between the pre and post intervention measuring points might be too short to detect improvements. Thus, more thorough procedures and tests of interventions in SEEs need to be carried out to improve these parameters.

SSEs utilise OHS less than larger enterprises and organisations and few workplace health interventions are reported by researchers. Therefore, there is a potential for OHS to develop specific strategies and services for SSE leaders on how to improve the working environment and health in their enterprises. Preferably, OHS could arrange networks for SSE leaders and employee representatives for discussions about workplace health activities and health-promoting leadership. In future research, it is important to document components in such interventions and evaluate them longitudinally by combining quantitative and qualitative methods.

\section{Methodological Considerations, Limitations and Strength}

First, the scales used in the present study are based on normative approaches to the subjects of psychosocial working conditions and health-related outcomes. However, the validation and reliability tests are all based on results from employees (leaders and coworkers) in enterprises and organisations that involve a large number of individuals. Individuals involved with SSEs of 20 or fewer employees may express opinions, values and attitudes that are quite different from those of the staff representatives in large-scale organisations. Accordingly, the employees of a small enterprise may be more involved in the production, activities and economy of the organisation than those of a large enterprise. Presumably, a smaller number of individuals will be more concerned about the enterprise's success or failure than a large number of employees. Furthermore, a smaller number of individuals likely feel a certain level of responsibility for the internal social community and are also more attentive to personal relationships between coworkers and leaders as well as between peer colleagues.

Second, the overall aim of the scales used was to measure several aspects of psychosocial working conditions and health. Thus, the suggestions above indicate a relatively strong impact on these aspects that must be accounted for in this study. Consequently, empirical validation PCA and reliability tests using Cronbach's alpha were executed in the present study to find potentially similar high test scores when compared to the equivalent original tests supporting the scales.

As expected, the empirical results displayed deviations from the desired values and low scores for some items in the selected scales when compared with earlier findings. Thus, a few items were excluded to obtain higher scores and more consistent indices.

Optimally, the selection criteria for the subjects taking part in the project should have been stricter, which demands randomisation and paring for the scientific design. An optimal solution is problematic, however, because the target group of coworkers and leaders then would have been difficult to reach. However, the selection of subjects for both the intervention and reference groups was similar concerning company size and sectors, but with regard to gender, there were more women in the Norwegian groups. The strengths of the study include the longitudinal research design, whereby the results for the same individual are followed before and after the performed interventions.

\section{Acknowledgements}

This project is a collaboration between the Department of Health Sciences, Mid Sweden University, and Levanger Hospital, Nord-Trøndelag Hospital Trust, Norway. The participants are acknowledged for their willingness to take part in the project. We wish to thank NAV Arbeidslivssenter (Norwegian Labour and Welfare Administration) for their cooperation and the OHS personnel in both Norway and Sweden for their contributions. The project was financed by AFA Insurance in Sweden (Dnr 130190).

\section{References}

Åkerstedt, T., Knutsson, A., Westerholm, P., Theorell, T., Alfredsson, L., \& Kecklund, G. (2002). Sleep disturbances, work stress and work hours: a cross-sectional study. Journal of psychosomatic research, 53(3), 741-748.

Andersson, M., \& Josephson, M. (2011). Swedish entrepreneurs' use of occupational health services. Workplace Health \& Safety, 59(10), 437.

Anderzén, I., \& Arnetz, B.B. (2005). The impact of a prospective survey-based workplace intervention program on employee health, biologic stress markers, and organizational productivity. Journal of occupational and environmental medicine, 47(7), 671-682. 
Aronsson, G., Johansen, V., Marklund, S., Rønning, R., \& Solheim, L.J. (2015). Sjukfrånvarons dimensioner: svensk-norska jämförelser och analyser.

Bjørnstad, O. (2013). Health-promoting workplaces in Norway. Barents Newsletter on Occupational Health and Safety, 16(1), 17-18.

Breuker, G. (2001). Small, healthy and competitive: new strategies for improved health in small and medium-sized enterprises: Report on the current status of workplace health promotion in small and mediumsized enterprises (SMEs). Essen: Federal Association of Company Health Insurance Funds.

Bringsen, A., Andersson, H.I., \& Ejlertsson, G. (2009). Development and quality analysis of the Salutogenic Health Indicator Scale (SHIS). Scand J Public Health, 37(1), 13-19. doi: 10.1177/1403494808098919

Christensen, M. (2012). Building Engagement and Healthy Organisations: Validation of the Nordic Questionnaire on Positive Organisational Psychology (N-POP), the Third Report from the Nordic Project: Nordic Council of Ministers.

Curran, J., \& Blackburn, R. A. (2001). Older people and the enterprise society: Age and self-employment propensities. Work, Employment \& Society, 15(04), 889-902.

Davidsson, P. (2016). The field of entrepreneurship research: Some significant developments. Contemporary Entrepreneurship (pp. 1728): Springer.

Dellve, L., Skagert, K., \& Vilhelmsson, R. (2007). Leadership in workplace health promotion projects: 1-and 2-year effects on long-term work attendance. The European Journal of Public Health, 17(5), 471-476.

Eakin, J., Lamm, F., \& Limborg, H. J. (2000). International perspective on the promotion of health and safety in small workplaces. Systematic occupational health and safety management: perspectives on an international development, pp. 227-247.

European Network for Workplace Health Promotion (ENWHP). (2007). Luxembourg Declaration on Workplace Health Promotion in the European Union.

European Network for Workplace Health Promotion (ENWHP). (2001). The Lisbon Statement on Workplace Health in Small and Medium-Sized Enterprises (SMEs).

Grawitch, M. J., Gottschalk, M., \& Munz, D. C. (2006). The path to a healthy workplace: A critical review linking healthy workplace practices, employee well-being, and organizational improvements. Consulting Psychology Journal: Practice and Research, 58(3), 129.

Griffin, B. L., Hall, N., \& Watson, N. (2005). Health at work in small and medium sized enterprises: Issues of engagement. Health Education, 105(2), 126-141.

Gunnarsson, K., Andersson, I.-M., \& Josephson, M. (2011). Entrepreneurs' approach and utilisation of Occupational Health Service.

Hasle, P., \& Limborg, H. J. (2006). A review of the literature on preventive occupational health and safety activities in small enterprises. Industrial Health, 44(1), 6-12.

Huuskonen, M. (2002). Health and safety in small enterprises: European strategies for managing improvement. Scandinavian Journal of Work, Environment \& Health, 28(5), 361-362.

Jensen, P. L. (2001). Risk assessment: A regulatory strategy for stimulating working environment activities? Human Factors and Ergonomics in Manufacturing \& Service Industries, 11(2), 101-116.

Kelloway, E.K., \& Barling, J. (2010). Leadership development as an intervention in occupational health psychology. Work \& Stress, 24(3), 260-279.

Källestål, C., Bjurvald, M., Menckel, E., Schærström, A., Schelp, L., \& Unge, C. (2004). Hälsofrämjande arbete på arbetsplatser. Effekter av interventioner refererade $i$ systematiska kunskapsöversikter och $i$ svenska rapporter.
Lindstrom, K., Schrey, K., Ahonen, G., \& Kaleva, S. (2000). The effects of promoting organizational health on worker well-being and organizational effectiveness in small and medium-sized enterprises. Healthy and productive work-An international perspective, 83-104.

Mattson, M. (2015). Promoting safety in organizations: The role of leadership and managerial practices.

Meggeneder, O. (2007). Style of management and the relevance for workplace health promotion in small and medium sized enterprises. Journal of Public Health, 15(2), 101-107.

Moser, M., \& Karlqvist, L. (2004). Small and medium sized enterprises: a literature review of workplace health promotion: Arbetslivsinstitutet.

Nilsson, P., Bringsen, A., Andersson, H.I., \& Ejlertsson, G. (2010). Development and quality analysis of the Work Experience Measurement Scale (WEMS). Work, 35(2), 153-161. doi: 10.3233/WOR-2010-0967.

Nordenmark, M., Vinberg, S., \& Strandh, M. (2012). Job control and demands, work-life balance and wellbeing among selfemployed men and women in Europe. Society, Health \& Vulnerability, 3.

Nyberg, A., Bernin, P., \& Theorell, T. (2005). The impact of leadership on the health of subordinates: National Institute for Working Life [Arbetslivsinstitutet] Stockholm.

Romanowska, J., Larsson, G., Eriksson, M., Wikström, B.-M., Westerlund, H., \& Theorell, T. (2010). Health effects on leaders and co-workers of an art-based leadership development program. Psychotherapy and psychosomatics, 80(2), 78-87.

Schmidt, L., Sjöström, J., \& Antonson, A.B. (2011). Vägar till framgångsrikt samarbete med företagshäslovård. Ways to a prosperous cooperation with the occupational health services.

Schwartz, S.H., Cieciuch, J., Vecchione, M., Davidov, E., Fischer, R., Beierlein, C.,. . . Demirutku, K. (2012). Refining the theory of basic individual values. Journal of Personality and Social Psychology, 103(4), 663.

Shain, M., \& Kramer, D. (2004). Health promotion in the workplace: framing the concept; reviewing the evidence. Occupational and environmental medicine, 61(7), 643-648.

Skakon, J., Nielsen, K., Borg, V., \& Guzman, J. (2010). Are leaders' well-being, behaviours and style associated with the affective well-being of their employees? A systematic review of three decades of research. Work \& Stress, 24(2), 107-139.

Stokols, D., McMahan, S., \& \& Philips, K. (2001). Workplace Health Promotion in Small Businesses. New York, NY: Delmar Thomson Learning.

Theorell, T., Emdad, R., Arnetz, B., \& Weingarten, A.-M. (2001). Employee effects of an educational program for managers at an insurance company. Psychosomatic Medicine, 63(5), 724733.

Torp, S., Eklund, L., \& Thorpenberg, S. (2011). Research on workplace health promotion in the Nordic countries: a literature review, 1986-2008. Global Health Promotion, 18(3), 15-22.

Walters, D. (2001). Health and safety in small enterprises: PIE-P. Lang.

Westmorland, M., \& Buys, N. (2002). Disability management in a sample of Australian self-insured companies. Disability and Rehabilitation, 24(14), 746-754.

Wilson, M.G., DeJoy, D.M., Jorgensen, C.M., Crump, C.J. (1999). Health promotion programs in small worksites: Results of a national survey. American Journal of Health Promotion, 13(6), 358365.

Vinberg, S. (2008). Workplace health interventions in small enterprises: a Swedish longitudinal study. Work, 30(4), 473482.

Vinberg, S., \& Gelin, G. (2005). Organizational and health performance in small enterprises in Norway and Sweden. Work, 24(3), 305-316. 
Witt, L. B., Olsen, D., \& Ablah, E. (2013). Motivating factors for small and midsized businesses to implement worksite health promotion. Health promotion practice, 14(6), 876884. von Thiele Schwarz, U., Lindfors, P., \& Lundberg, U. (2008). Healthrelated effects of worksite interventions involving physical exercise and reduced workhours. Scandinavian journal of work, environment \& health, 179-188. 